\title{
PILLS, INJECTIONS AND AUDIOTAPES: REACHING COUPLES IN PAKISTAN
}

\author{
MARTINE COLLUMBIEN AND MEGAN DOUTHWAITE \\ Centre for Population Studies, L ondon School of $\mathrm{H}$ ygiene and Tropical M edicine, \\ 49-51 Bedford Square, L ondon W C 1B 3DP
}

\begin{abstract}
Summary. A n innovative social marketing intervention in Pakistan distributes audiocassettes via chemist shops and Lady Health Visitors (LHVs) to reach women in a segregated society with accurate information on hormonal contraceptives. Operations research was done to assess the utility of the cassette in knowledge dissemination and adoption of hormonal use. In total 187 structured questionnaires were completed with couples who had obtained a cassette. L isteners were significantly more knowledgeable than non-listeners about correct use of hormonals ( $O R=8.6$ for women and $O R=12.7$ for men). Hormonal use increased from $12 \%$ to $25 \%$. L HVs also organized discussion groups for women, and attending such a chat group was the strongest predictor for adoption of pills and injectables (OR $=4 \cdot 15)$. Equivalent male groups are suggested to reach apprehensive men. By providing accurate information to urban couples and by acquiring a knowledgeable critical mass of satisfied users, the cassette could be a powerful catalyst to further contraceptive diffusion.
\end{abstract}

\section{Background}

Programmatic effort has long been deemed unsuccessful in satisfying unmet need for family planning in Pakistan. While in 1991 unmet need in Pakistan was one of the highest in the world, $74 \%$ of women in need of contraception did not intend to use a method in the future (Westoff \& Bankole, 1995). By providing increased access to basic family planning services, small community-based distribution programmes have demonstrated large rises in contraceptive use, confirming the inadequacy of existing services (Shelton et al., 1999). The fertility transition did finally start during the 1990s, and contraceptive use in Pakistan doubled from $12 \%$ to $24 \%$ during the period 1990-91 to 1996-97 (Hakim, Cleland \& Bhatti, 1998). This recent shift has been attributed mainly to changes in demand for children, together with changes in social, psychic and cultural costs of contraception, while improvements in family planning services only made a minor contribution (Sathar \& Casterline, 1998). To improve service provision, the Government of Pakistan launched two initiatives with new 
cadres of community-based female workers in 1992-1994. A Iso, through private sector initiatives, access to contraception in urban areas has improved. Contraceptive social marketing started in the late 1980s with radio and television campaigns promoting family planning (D avies \& A gha, 1997).

In 1996-97 over $85 \%$ of currently married women in urban areas were aware of pills or injections, and $70 \%$ knew where to obtain them. N evertheless, with little over $1 \%$ of couples using hormonal methods, these were the least popular modern methods (Hakim, Salway \& M umtaz, 1998). The fear of side-effects and concerns about the efficacy of modern methods stand out as reasons for non-use or discontinuation of contraception among Pakistani couples (Population Council, 1997). A survey conducted among clients of the village-based F amily Planning Worker found that fewer than half of current users of pills, injectables and IU D s correctly identified side-effects associated with their method (Population Council and Ministry of Population W elfare, 1996). These findings underline the need for correct information, improved follow-up and reassurance about the use of modern contraceptive methods.

Segregation of the sexes, with attendant social barriers, poses a major challenge to reaching women directly. Qualitative data from Punjab have suggested that the restricted mobility of women is an important barrier to accessing family planning services (K han, 1999), and based on the 1996-1997 national fertility survey, several indicators of autonomy were significantly associated with current use of contraception (Hakim \& Salway, 1999). In a country where women's mobility is restricted, their decision-making power limited, and where less than one-quarter can read, getting accurate and complete information to women and men about contraception poses a particular challenge. Men's or husbands' roles within this social structure are of particular importance. Davies, M itra \& Schellstede (1987) pointed out that in the commercial distribution of oral contraception in Bangladesh, husbands are providers of supplies and information to their wives. However, the pharmacists consulted by the husbands were poor instructors on correct use, and they perceived themselves as providers of medicine rather than providers of advice. $M$ en could therefore not adequately advise their wives on correct use (D avies et al., 1987). In Pakistan a social marketing project, selling a low-dose pill and a 3-month injectable through existing commercial distribution infrastructure in urban and peri-urban areas, adopted an innovative approach of disseminating information using a cassette, thereby exploiting the high ownership of cassette players among Pakistanis, which is higher than that of radios. A $n$ audiocassette provides the potential answer to both the problems pointed out by Davies et al. (1987): that providers fail as good instructors and that the ultimate users are often not the purchasers of supplies.

The cassette, available in five regional languages, imparts information about the pill and injection ( 15 minutes on each method) through a simulated interaction between a provider and a couple interested in birth spacing. The menstrual cycle and correct use of both methods are discussed, as well as the side-effects and detailed contra-indications to comply with WHO eligibility criteria for contraceptive use (World Health Organization, 1996). Information disseminated through the cassette was not subject to the same censorship rules as information on the television. Cassettes ensure accuracy and consistency of information, and have the added benefit that they can be listened to repeatedly, in the privacy of clients' homes, and jointly 
as a couple, thus enhancing the potential for husband-wife communication regarding contraceptive use. Since tapes can easily be passed on to neighbours or friends interested in family planning, they serve to encourage demand as well as provide accessible reassurance on effective use of hormonal contraception whenever needed.

The cassette was included free with hormonal contraceptives, as well as being sold separately for a nominal amount of $5 \mathrm{Rs}$ (approximately US\$ $0 \cdot 1$ ). The production cost of the cassette was nearly US\$0.4 at the start of the intervention, but has decreased to US\$0.2 per tape after scaling up. Distribution involved no extra costs since it used the same channels as for the contraceptives. Products and audiocassettes were available through pharmacies and female paramedics - normally a (private) Lady Health Visitor ( $\mathrm{LHV})$ - resident in the neighbourhood. In addition a programme of neighbourhood discussion groups was established which centred on the audiocassette. These M ohalla Sangat chat groups were led by the LH V, who brought women together in a participant's home. Sessions included listening to the tape, discussion, questions and answers, and opportunities for individuals to consult the LHV afterwards, and obtain the cassette. The L HVs were also encouraged to talk to husbands, but men never participated in chat groups. In a segregated society that restricts female mobility, it was assumed that men would buy the cassettes from chemist shops while women would get it from LHVs.

Pakistan is thought to be the only country where audiocassettes to promote family planning methods have been distributed on a national level. The main aim of this paper is to report on operations research done during the initial months of the intervention, before it was scaled up to the national level. Simple programme questions to be answered were: Do both men and women listen to the cassette? W hat are the dynamics of listening - do couples discuss the tape amongst themselves and with others? D o listeners retain correct knowledge of information imparted, and what is its effect on subsequent uptake of contraception among people who obtained the cassette? A re the discussion groups held by LHVs a worthwhile addition to the cassette?

\section{Data and methods}

Since contraceptive decisions involve both partners, couple interviews were done to assess whether the audiocassette was well received by both men and women and effective in disseminating information. A male surveyor interviewed the husband and a female surveyor interviewed the wife. The study was conducted about 6 months after the launch of the project, when only a few people had had the chance to obtain the tape. This precluded a population-based study and the most effective way of sampling buyers of cassettes was at the point of delivery. Chemists and L H V s in the cities of $\mathrm{F}$ aisalabad and Larkana were asked to collect names and addresses of men and women who obtained the cassette. A third group was sampled with the help of key informants in the community who knew people that had obtained the cassette. M ost of these people were given the tape by friends, relatives or neighbours, while $20 \%$ had received it from a doctor. This group was expected to be qualitatively different from the presumably more motivated couples who had taken the initiative to buy the tape. 
D uring a first screening interview, names were followed up to ensure eligibility in the study, i.e. couples in which the woman was of reproductive age, and from which consent was obtained to conduct interviews with both partners at a later date. Of the 349 respondents of the screening questionnaire, 11\% declined consent for a further interview. Of 184 women contacted two refused a second interview, compared with $22 \%$ of the men (37 out of 165 ).

Data collection was conducted during December 1997, and the fieldwork was curtailed by the start of Ramadan. In total 187 husband-and-wife interviews were successfully completed. Of these, 31\% couples were sampled via the chemist stores, $33 \%$ obtained the tape from L H V s and 36\% had been given the tape by others. The average time between acquiring the cassette and the couple interview was 4 months.

This article presents descriptive statistics and chi-square analysis of the effect of explanatory variables on levels of knowledge, attitudes and contraceptive use. Although the study uses a cross-sectional design and cannot assess levels of knowledge and attitudes before exposure to the tape, information was gathered on the contraceptive method used at the time the tape was acquired. Logistic regression models are used for evaluating the net effect of explanatory variables on knowledge and adoption of a hormonal method and the results are expressed as odds ratios. A n odds ratio larger than 1 indicates that the likelihood of the couple using contraception is greater than for the reference category (which has an odds ratio of 1 ). For some key information, the proportion of couples giving consistent answers is presented, together with the $\kappa$ statistic, which corrects for chance agreement. A $\kappa$ value of 0 represents no agreement beyond chance, 0.4-0.75 represents good agreement, while values above 0.75 represent excellent couple agreement beyond chance. Statistical analysis was conducted using SPSS 6.1.

\section{R esults}

Profile of the sample

The people who obtained the tape were a self-selected group of couples interested in family planning. The study population was relatively older, better educated and of higher parity than a representative sample of urban couples. Table 1 gives the sociodemographic characteristics of the men and women interviewed, and compares them with those of urban women from the 1997 Pakistan Fertility and Family Planning Survey (PFFPS). N early $60 \%$ of women were over 30 and more than half of husbands were older than 35.

F ifty-eight per cent of women and $87 \%$ of men had attended school, and $60 \%$ and $89 \%$ respectively were literate (could read and write a simple letter). Compared with urban women interviewed in the 1997 PFFPS there are fewer women with either no education or higher education. M en and women reported similar levels of monthly household income, with more than half of couples reporting incomes of 2000-4000 R s. Although more than three-quarters of couples had three children or more, there were some small families with one and two children, and one couple was childless.

Twenty-two women were pregnant at the time of the survey. Eighty-five per cent of women appeared to be in need of contraception: $56 \%$ wanted no more children, 
Table 1. Sociodemographic profile of sample

\begin{tabular}{|c|c|c|c|}
\hline & \multicolumn{2}{|c|}{ Study sample } & 1997 PFFPS \\
\hline & $\begin{array}{l}\text { Women } \\
(n=187)\end{array}$ & $\begin{array}{c}\text { M en } \\
(n=187)\end{array}$ & $\begin{array}{l}\text { Currently married urban women } \\
\qquad(n=2244)\end{array}$ \\
\hline \multicolumn{4}{|l|}{ A ge distribution } \\
\hline$<25$ & $13 \cdot 4$ & $4 \cdot 3$ & $26 \cdot 0$ \\
\hline $25-29$ & $29 \cdot 4$ & $18 \cdot 2$ & $25 \cdot 8$ \\
\hline $30-34$ & $27 \cdot 8$ & $25 \cdot 7$ & $23 \cdot 2$ \\
\hline $35-39$ & $25 \cdot 7$ & $24 \cdot 1$ & $19 \cdot 8$ \\
\hline $40+$ & $3 \cdot 7$ & $27 \cdot 8$ & $14 \cdot 2$ \\
\hline \multicolumn{4}{|l|}{ Education } \\
\hline No education & $42 \cdot 2$ & $13 \cdot 4$ & $49 \cdot 2$ \\
\hline Primary & $18 \cdot 7$ & $18 \cdot 2$ & $13 \cdot 3$ \\
\hline M iddle & $12 \cdot 8$ & $13 \cdot 4$ & $9 \cdot 7$ \\
\hline Secondary & $24 \cdot 6$ & $42 \cdot 8$ & $11 \cdot 1$ \\
\hline Higher & $1 \cdot 6$ & $12 \cdot 3$ & $16 \cdot 6$ \\
\hline \multicolumn{4}{|l|}{ Literacy } \\
\hline Literate & $60 \cdot 4$ & $88 \cdot 8$ & $42 \cdot 6$ \\
\hline \multicolumn{4}{|c|}{ M onthly income (Rs) } \\
\hline$<2000$ & 9.6 & $4 \cdot 8$ & na \\
\hline $2001-4000$ & $54 \cdot 5$ & $59 \cdot 4$ & na \\
\hline $4001-6000$ & $20 \cdot 9$ & $23 \cdot 5$ & na \\
\hline$>6000$ & $15 \cdot 0$ & $12 \cdot 3$ & na \\
\hline \multicolumn{4}{|l|}{ Living children } \\
\hline 0 & 0.5 & 0.5 & $10 \cdot 5$ \\
\hline 1 & $10 \cdot 2$ & $10 \cdot 2$ & $13 \cdot 9$ \\
\hline 2 & $12 \cdot 3$ & $12 \cdot 3$ & $12 \cdot 7$ \\
\hline 3 & $21 \cdot 4$ & $21 \cdot 4$ & $13 \cdot 9$ \\
\hline $4-5$ & $31 \cdot 6$ & $31 \cdot 6$ & $24 \cdot 7$ \\
\hline $6+$ & $24 \cdot 1$ & $24 \cdot 1$ & $24 \cdot 3$ \\
\hline
\end{tabular}

na, not applicable.

$20 \%$ wanted to wait for at least 2 years before the next birth and $8 \%$ were undecided on whether to have another child. M ale reports indicated that $79 \%$ of couples were in need of contraception, with fewer men wanting to limit the current family size (48\%). A nalysis of couple agreement shows that only thirteen couples $(<7 \%)$ had discordant needs for contraception $(\kappa=0.77)$. In all but one couple, the wife was the one classified needing contraception based on her reported fertility preferences.

Dynamics of cassette buying and listening

Key features of obtaining and listening to the cassette by source of tape are summarized in Table 2. In this sample nearly half of the cassettes (47\%) were obtained by women. U nexpectedly, 21 women got the tape from a chemist, whereas seven men 
Table 2. K ey features of obtaining and listening to the cassette by source

\begin{tabular}{lrrr}
\hline & \multicolumn{3}{c}{ Source of cassette } \\
\cline { 2 - 4 } & $\begin{array}{c}\text { L H V } \\
(n=61)\end{array}$ & $\begin{array}{c}\text { Chemist } \\
(n=57)\end{array}$ & $\begin{array}{c}\text { Others } \\
(n=69)\end{array}$ \\
\hline Percentage of cassettes obtained by women & 88 & 34 & 25 \\
Percentage of women who attended chat group & 70 & 13 & 10 \\
Percentage of women who listened to tape & 93 & 93 & 67 \\
Percentage of men who listened to tape & 42 & 56 & 78 \\
Percentage of women who discussed the tape* & 79 & 68 & 61 \\
Percentage of men who discussed the tape* & 100 & 100 & 100 \\
\hline
\end{tabular}

*A mong those who listened.

obtained the cassette from an LHV. An explanation for the higher than expected number of women obtaining cassettes through chemists is the fact that one of the stores that collected addresses was close to a hospital and therefore visited by female patients or visitors.

Thirty per cent of women had attended a M ohalla Sangat chat group, but attendance was considerably higher among women who got the tape from an LHV (70\%). Only $62 \%$ of husbands of participating women correctly reported her attendance; $24 \%$ did not know and $14 \%$ stated that their wife had not been to a meeting.

M ost men (85\%) and women (79\%) did not discuss the decision to obtain the cassette with their spouse prior to getting it. D iscussion with spouse prior to purchase was as low as 10\% for those who got the tape from the chemist. A bout $15 \%$ of respondents had listened to a cassette before they got one for themselves.

M ore women (83\%) than men $(60 \%)$ listened to the cassette. $M$ en were more likely to listen if they had been the partner to obtain it, and likewise with women. H owever, women were much more likely to listen to the cassette if their husband had obtained it $(78 \%)$, than husbands were if their wives had obtained it (33\%). J ust over $40 \%$ of men and women reported that both partners listened to the cassette. However, not all respondents knew whether their partner had played the tape, and $11 \%$ of men and $6 \%$ of women stated incorrectly that their partner had not listened. The main reason given for not listening to the cassette was lack of time (79\% for men versus $36 \%$ for women), while lack of privacy was mentioned by only three women and four men. In couples where both partners had listened to the tape, generally the person who brought the cassette home listened to it first (50\%). In total, only $19 \%$ of couples had listened to the tape together, while $35 \%$ of women reported discussing the content of the tape with her husband.

All men who listened reported that they had discussed the content of the cassette with at least one other person, whereas only $30 \%$ of women reported that they had spoken to anyone about it. Only half of respondents still had the cassette and, of these, three-quarters said that they would listen to it in the future. $\mathrm{H}$ alf of respondents 
Table 3. Proportion of respondents giving correct answers to questions regarding use of hormonal methods according to whether they had listened to the tape

\begin{tabular}{|c|c|c|c|c|}
\hline & \multicolumn{2}{|c|}{ W omen } & \multicolumn{2}{|c|}{ M en } \\
\hline & $\begin{array}{l}\text { Listened to } \\
\text { tape } \\
(n=156)\end{array}$ & $\begin{array}{l}\text { Did not } \\
\text { listen } \\
(n=31)\end{array}$ & $\begin{array}{c}\text { Listened to } \\
\text { tape } \\
(n=112)\end{array}$ & $\begin{array}{c}\text { Did no } \\
\text { listen } \\
(n=75)\end{array}$ \\
\hline On what day in menstrual cycle start pill? & $60 \cdot 9 *$ & $35 \cdot 5$ & $60 \cdot 7 * *$ & 8.0 \\
\hline How often should woman take the pill? & $89 \cdot 7 * *$ & $38 \cdot 7$ & $76 \cdot 8^{* *}$ & $14 \cdot 7$ \\
\hline R egimen for forgotten pill & $84 \cdot 6^{* *}$ & $38 \cdot 7$ & $50 \cdot 9 * *$ & $14 \cdot 7$ \\
\hline At what time in menstrual cycle start injection? & $77 \cdot 6 * *$ & $32 \cdot 3$ & $60 \cdot 7 * *$ & $13 \cdot 3$ \\
\hline A fter how many months need next injection? & $82 \cdot 7 * *$ & $35 \cdot 5$ & $67 \cdot 9 * *$ & $18 \cdot 7$ \\
\hline Can woman breast-feeding 2-month-old baby & & & & \\
\hline use the injectable? & $55 \cdot 1 *$ & $25 \cdot 8$ & $30 \cdot 4 * *$ & $1 \cdot 3$ \\
\hline
\end{tabular}

Pearson chi-square: $* p<0.002, * * p<0.00001$.

who no longer had the tape had given it away, and $13 \%$ of those who still had the tape had at some point lent it to someone else.

Knowledge of and attitudes towards hormonals

The cassette includes discussion on side-effects, contra-indications and correct use. This includes clear instructions to start the pill on the first day of menstruation and what to do when a pill is missed. I mpact of the cassette on respondents' knowledge is assessed by comparing responses from men and women who had listened to the cassette with those who had not. Based on the assumption that prior to listening levels of knowledge were similar in these subgroups, this provides a proxy measure of change in knowledge. Table 3 presents the proportions of respondents who gave correct answers to questions about pill and injectable use based on information supplied on the tape. In general, women were more knowledgeable than men, and respondents who had listened to the cassette were significantly more knowledgeable than those who had not.

The doctor on the tape discussed other benefits of using oral contraception beyond preventing pregnancies. Respondents were asked their (unprompted) knowledge of these additional benefits. The majority of respondents who had not listened to the cassette knew of no benefits ( $80 \%$ of the women and $93 \%$ of men). A mong those that had listened, $69 \%$ of the women and $46 \%$ of men could recall at least one additional benefit. The most common benefit mentioned by women was 'the quick return to fertility' (46\%) and 'regular menstruation' (38\%).

A knowledge score was constructed, taking the value of 1 when the respondent answered at least four out of the six questions (in Table 3) correctly and a value of 0 otherwise. Women scored higher than men (72\% versus $63 \%)$, and respondents who 
Table 4. U nadjusted and adjusted odds ratios of knowledge by tape characteristics and background variables

\begin{tabular}{|c|c|c|c|c|}
\hline & \multicolumn{4}{|c|}{ Correct knowledge of use of hormonal contraception } \\
\hline & \multicolumn{2}{|c|}{ Women $(n=100)$} & \multicolumn{2}{|c|}{ M en $(n=100)$} \\
\hline & Model 1 & M odel 2 & Model 1 & M odel 2 \\
\hline \multicolumn{5}{|l|}{ Listened to tape } \\
\hline Y es & $12 \cdot 08 * *$ & $8 \cdot 57 * *$ & $12 \cdot 49 * *$ & $12 \cdot 67 * *$ \\
\hline No & 1 & 1 & 1 & 1 \\
\hline \multicolumn{5}{|l|}{ Source of tape } \\
\hline LHV & & 1 & & 1 \\
\hline Chemist store & & $1 \cdot 80$ & & $2 \cdot 62 *$ \\
\hline Other & & 0.49 & & $2 \cdot 29$ \\
\hline \multicolumn{5}{|c|}{ A ttended chat group } \\
\hline Y es & & 1.06 & & - \\
\hline No & & 1 & & - \\
\hline \multicolumn{5}{|l|}{ A ge } \\
\hline$<30$ & & 1 & & 1 \\
\hline $30-34$ & & 0.69 & & $1 \cdot 18$ \\
\hline $35+$ & & $0 \cdot 72$ & & 0.99 \\
\hline \multicolumn{5}{|c|}{ H ousehold income (Rs) } \\
\hline$\leq 4000$ & & 1 & & 1 \\
\hline$>4000$ & & 0.84 & & $1 \cdot 30$ \\
\hline \multicolumn{5}{|l|}{ Education } \\
\hline None & & 1 & & 1 \\
\hline Primary/middle & & $2 \cdot 06$ & & 0.61 \\
\hline Secondary+ & & $4 \cdot 36 *$ & & $1 \cdot 27$ \\
\hline
\end{tabular}

$* p<0.05 ; * * p<0.0001$.

had listened to the tape were twelve times more likely than non-listeners to answer at least four questions correctly. From the multivariate analysis presented in Table 4 it can be seen that, once attendance of a discussion group (women only), source of tape and sociodemographic variables are controlled for, the odds ratio decreases to 8.6 for women. Secondary education increased the likelihood of correct knowledge by 4.3 times, while attending a chat group had no additional effect on knowledge. F or men, obtaining the tape from the chemist store was associated with an increased likelihood of correct knowledge, while education of husband had no effect.

A ttitudes towards hormonals were assessed by the reported intention to use pills or injections in the future. Including current users, $40 \%$ of women who had listened to the cassette reported that they were very likely to use hormonals in the future compared with $26 \%$ of women who had not listened to the cassette (Table 5). The negative attitude expressed as being 'very unlikely future users' was three times higher for non-listeners. A mong men, however, having listened to the cassette was associated 
Table 5. Intention (for wife) to use hormonal contraception in the future, according to whether they had listened to the tape

\begin{tabular}{|c|c|c|c|c|}
\hline & \multicolumn{2}{|c|}{ W omen } & \multicolumn{2}{|c|}{ M en } \\
\hline & $\begin{array}{c}\text { Listened to } \\
\text { tape } \\
(n=156)\end{array}$ & $\begin{array}{l}\text { Did not listen } \\
\text { to tape } \\
(n=31)\end{array}$ & $\begin{array}{c}\text { Listened to } \\
\text { tape } \\
(n=112)\end{array}$ & $\begin{array}{c}\text { Did not listen } \\
\text { to tape } \\
(n=75)\end{array}$ \\
\hline Very likely & $39 \cdot 7$ & $25 \cdot 8$ & $22 \cdot 3$ & $26 \cdot 7$ \\
\hline Somewhat likely & $30 \cdot 8$ & $19 \cdot 4$ & $36 \cdot 6$ & $37 \cdot 3$ \\
\hline Do not know & $12 \cdot 2$ & $12 \cdot 9$ & $10 \cdot 7$ & $16 \cdot 0$ \\
\hline Somewhat unlikely & $3 \cdot 8$ & $3 \cdot 2$ & $10 \cdot 7$ & 8.0 \\
\hline Very unlikely & $13 \cdot 5$ & $38 \cdot 7$ & $19 \cdot 6$ & $12 \cdot 0$ \\
\hline
\end{tabular}

with a more negative attitude to future use of hormonals. $M$ en who had received the tape from others were more negative than those who got it from either an LHV or chemist store.

\section{Contraceptive use}

The contraceptive prevalence rate was high, as would be expected from this subgroup of urban couples who were motivated enough to obtain a cassette on hormonal methods. Women report slightly higher use than men $449 \%$ and $47 \%$ respectively), and $91 \%$ of couples gave consistent answers on current contraceptive use $(\kappa=0.83)$. A mong current users, more than $70 \%$ had been practising family planning at the time they got the tape.

Table 6 presents differentials in current use and use at the time the tape was acquired according to selected explanatory factors; the relative increase in contraceptive use and the proportion of respondents currently in need of contraception are also given. Women who got the cassette from an L H V, attended a chat group, or obtained the cassette themselves, were almost twice as likely to be current users compared with other women. However, these differentials in contraceptive prevalence partly reflect a selection effect, as can be inferred from the data on use at the time the couple acquired the tape. A more motivated group of couples who were already practising family planning were more likely to attend a chat group and to get the tape from an LHV.

$U$ se of any method increased by $23 \%$ among women and $24 \%$ among men during the period between acquiring the cassette and the survey, which was on average about 4 months. There was a $42 \%$ increase in contraceptive use among couples who had obtained the tape from an LHV, and a $21 \%$ increase among couples who had bought it from a chemist store. There was no increase in use for those who got the tape from other sources. While the proportions currently in need of contraception were different among these three groups, they were lowest among those couples who got the cassette from a chemist shop, and highest for the LHV subgroup. People who obtained the 
Table 6. Change in contraceptive prevalence since time couple acquired the tape, by selected characteristics

\begin{tabular}{|c|c|c|c|c|c|c|c|c|}
\hline & \multicolumn{4}{|c|}{ W omen } & \multicolumn{4}{|c|}{$M$ en } \\
\hline & $\begin{array}{c}\text { Current } \\
\text { use }\end{array}$ & $\begin{array}{l}U \text { se at } \\
\text { time of } \\
\text { getting } \\
\text { tape }\end{array}$ & $\begin{array}{c}\% \\
\text { increase }\end{array}$ & $\begin{array}{l}\% \text { in } \\
\text { need of } \\
\text { contra- } \\
\text { ception }\end{array}$ & $\begin{array}{c}\text { Current } \\
\text { use }\end{array}$ & $\begin{array}{l}U \text { se at } \\
\text { time of } \\
\text { getting } \\
\text { tape }\end{array}$ & $\begin{array}{c}\% \\
\text { increase }\end{array}$ & $\begin{array}{l}\% \text { in } \\
\text { need of } \\
\text { contra- } \\
\text { ception }\end{array}$ \\
\hline All & $48 \cdot 7$ & 39.6 & $23 \cdot 0$ & 85 & $46 \cdot 5$ & $37 \cdot 4$ & $24 \cdot 3$ & 79 \\
\hline $\begin{array}{l}\text { Source of tape } \\
\text { LHV } \\
\text { Chemist store } \\
\text { Other }\end{array}$ & $\begin{array}{l}77 \cdot 2 \\
37 \cdot 7 \\
34 \cdot 8\end{array}$ & $\begin{array}{l}54 \cdot 4 \\
31 \cdot 1 \\
34 \cdot 8\end{array}$ & $\begin{array}{r}41 \cdot 9 \\
21 \cdot 2 \\
0 \cdot 0\end{array}$ & $\begin{array}{l}93 \\
77 \\
84\end{array}$ & $\begin{array}{l}68 \cdot 4 \\
39 \cdot 3 \\
34 \cdot 8\end{array}$ & $\begin{array}{l}45 \cdot 6 \\
34 \cdot 4 \\
33 \cdot 3\end{array}$ & $\begin{array}{r}50 \cdot 0 \\
14 \cdot 2 \\
4 \cdot 5\end{array}$ & $\begin{array}{l}88 \\
71 \\
78\end{array}$ \\
\hline $\begin{array}{l}\text { Buyer of tape } \\
\text { Wife } \\
\text { Husband }\end{array}$ & $\begin{array}{l}61 \cdot 4 \\
37 \cdot 4\end{array}$ & $\begin{array}{l}44 \cdot 3 \\
35 \cdot 4\end{array}$ & $\begin{array}{r}38.6 \\
5.6\end{array}$ & $\begin{array}{l}93 \\
77\end{array}$ & $\begin{array}{l}52 \cdot 3 \\
41 \cdot 4\end{array}$ & $\begin{array}{l}40 \cdot 9 \\
34 \cdot 3\end{array}$ & $\begin{array}{l}27 \cdot 9 \\
20 \cdot 7\end{array}$ & $\begin{array}{l}86 \\
72\end{array}$ \\
\hline $\begin{array}{l}\text { Wife attended cha } \\
\text { Y es } \\
\text { N o } \\
\text { Don't know }\end{array}$ & $\begin{array}{l}78 \cdot 2 \\
36 \cdot 4 \\
-\end{array}$ & $\begin{array}{l}56 \cdot 4 \\
32 \cdot 6 \\
-\end{array}$ & $\begin{array}{l}38 \cdot 7 \\
11 \cdot 7\end{array}$ & $\begin{array}{l}89 \\
83\end{array}$ & $\begin{array}{l}71 \cdot 1 \\
38 \cdot 6 \\
42 \cdot 6\end{array}$ & $\begin{array}{l}42 \cdot 1 \\
36 \cdot 4 \\
36 \cdot 1\end{array}$ & $\begin{array}{r}68 \cdot 9 \\
6 \cdot 0 \\
18 \cdot 0\end{array}$ & $\begin{array}{l}84 \\
73 \\
84\end{array}$ \\
\hline $\begin{array}{l}\text { Listened to tape } \\
\text { Y es } \\
\text { No }\end{array}$ & $\begin{array}{l}51 \cdot 9 \\
32 \cdot 3\end{array}$ & $\begin{array}{l}41 \cdot 0 \\
32 \cdot 3\end{array}$ & $\begin{array}{r}26.6 \\
0.0\end{array}$ & $\begin{array}{l}85 \\
84\end{array}$ & $\begin{array}{l}40 \cdot 2 \\
56 \cdot 0\end{array}$ & $\begin{array}{l}36 \cdot 6 \\
38 \cdot 7\end{array}$ & $\begin{array}{r}9 \cdot 8 \\
44 \cdot 7\end{array}$ & $\begin{array}{l}74 \\
85\end{array}$ \\
\hline $\begin{array}{l}\text { A ge } \\
\qquad \begin{array}{l}<25 \\
25-29 \\
30-34 \\
35-39 \\
40+\end{array}\end{array}$ & $\begin{array}{l}52 \cdot 0 \\
54 \cdot 5 \\
61 \cdot 5 \\
31 \cdot 3 \\
14 \cdot 3\end{array}$ & $\begin{array}{l}36 \cdot 0 \\
41 \cdot 8 \\
50 \cdot 0 \\
27 \cdot 1 \\
42 \cdot 9\end{array}$ & $\begin{array}{r}44 \cdot 4 \\
30 \cdot 4 \\
23 \cdot 0 \\
15 \cdot 5 \\
-66 \cdot 7\end{array}$ & $\begin{array}{r}76 \\
71 \\
89 \\
100 \\
86\end{array}$ & $\begin{array}{l}50 \cdot 0 \\
50 \cdot 0 \\
50 \cdot 0 \\
44 \cdot 4 \\
42 \cdot 3\end{array}$ & $\begin{array}{l}12 \cdot 5 \\
44 \cdot 1 \\
41 \cdot 7 \\
37 \cdot 8 \\
32 \cdot 7\end{array}$ & $\begin{array}{r}300 \cdot 0 \\
13 \cdot 4 \\
19 \cdot 9 \\
17 \cdot 5 \\
29 \cdot 4\end{array}$ & $\begin{array}{l}63 \\
68 \\
71 \\
80 \\
94\end{array}$ \\
\hline $\begin{array}{l}\text { E ducation } \\
\text { No education } \\
\text { Primary/middle } \\
\text { Secondary+ }\end{array}$ & $\begin{array}{l}32 \cdot 9 \\
54 \cdot 2 \\
67 \cdot 3\end{array}$ & $\begin{array}{l}26 \cdot 6 \\
45 \cdot 8 \\
53 \cdot 1\end{array}$ & $\begin{array}{l}23 \cdot 7 \\
18 \cdot 3 \\
26 \cdot 7\end{array}$ & $\begin{array}{l}84 \\
85 \\
86\end{array}$ & $\begin{array}{l}16 \cdot 0 \\
44 \cdot 1 \\
55 \cdot 3\end{array}$ & $\begin{array}{l}16 \cdot 0 \\
33 \cdot 9 \\
44 \cdot 7\end{array}$ & $\begin{array}{r}0 \cdot 0 \\
30 \cdot 1 \\
23 \cdot 7\end{array}$ & $\begin{array}{l}76 \\
86 \\
75\end{array}$ \\
\hline $\begin{array}{l}\text { H ousehold income } \\
\quad \leq 4000 \\
>4000\end{array}$ & $\begin{array}{l}36 \cdot 7 \\
70 \cdot 1\end{array}$ & $\begin{array}{l}35 \cdot 0 \\
47 \cdot 8\end{array}$ & $\begin{array}{r}4.9 \\
46.7\end{array}$ & $\begin{array}{l}85 \\
84\end{array}$ & $\begin{array}{l}38 \cdot 3 \\
61 \cdot 2\end{array}$ & $\begin{array}{l}36 \cdot 7 \\
38 \cdot 8\end{array}$ & $\begin{array}{r}4.4 \\
57 \cdot 7\end{array}$ & $\begin{array}{l}82 \\
72\end{array}$ \\
\hline
\end{tabular}

The reports of men and women refer to the same couples for source of tape, buyer of tape and city; for the other differentials it reflects the respondent's own status and men and women in the subgroups are not necessarily husband and wife.

Estimates based on fewer than 20 respondents are in italics. 
Table 7. M ethod-specific use: currently and at the time the couple acquired the tape

\begin{tabular}{|c|c|c|c|c|c|c|c|c|}
\hline & \multicolumn{4}{|c|}{ W omen } & \multicolumn{4}{|c|}{ M en } \\
\hline & \multicolumn{2}{|c|}{ Current use } & \multicolumn{2}{|c|}{$\begin{array}{l}\text { U se at time tape } \\
\text { was obtained }\end{array}$} & \multicolumn{2}{|c|}{ Current use } & \multicolumn{2}{|c|}{$\begin{array}{l}\text { U se at time tape } \\
\text { was obtained }\end{array}$} \\
\hline & $\%$ & (n) & $\%$ & (n) & $\%$ & (n) & $\%$ & (n) \\
\hline Pills & $16 \cdot 0$ & (30) & 8.6 & (16) & $11 \cdot 8$ & (22) & 5.9 & (11) \\
\hline Injectables & $9 \cdot 1$ & (17) & $3 \cdot 2$ & (6) & 9.6 & (18) & $3 \cdot 7$ & (7) \\
\hline IUDs & $7 \cdot 5$ & (14) & 8.6 & (16) & $7 \cdot 0$ & (13) & $7 \cdot 5$ & (14) \\
\hline Condoms & 8.0 & (15) & $12 \cdot 3$ & (23) & 8.6 & (16) & $11 \cdot 8$ & (22) \\
\hline F emale sterilization & 1.6 & (3) & $2 \cdot 1$ & (4) & $2 \cdot 1$ & (4) & $2 \cdot 1$ & (4) \\
\hline W ithdrawal/rhythm & $6 \cdot 4$ & $(12)$ & $4 \cdot 8$ & (9) & $7 \cdot 5$ & (14) & $6 \cdot 4$ & (12) \\
\hline Not using & $51 \cdot 3$ & (91) & $60 \cdot 4$ & (74) & $53 \cdot 5$ & (87) & $62 \cdot 6$ & (70) \\
\hline
\end{tabular}

(n) refers to the actual number of respondents who are using.

tape from the LHV or the chemist store were thus more motivated to start using a method, whereas those who were given it by a friend were not acting on their fertility preferences to the same extent.

Contraceptive use increased by $39 \%$ among women who attended a chat group, and when husbands reported their wife had attended a meeting there was a $69 \%$ increase. Current use was lower among couples where the husband had listened to the tape $(40 \%)$ compared with those where he had not $(56 \%)$. Women who had not listened to the cassette did not start contraception, while there was a $45 \%$ increase in contraceptive use among couples with husbands who had not listened.

Women aged 30-34 years were most likely to use family planning, although over $50 \%$ of women in their 20 s were practising birth control. Current use varied by educational level in the expected direction, although the relative increase was not very different. Contraceptive use at the time of the survey was significantly higher for women in the higher income bracket (70\% versus 37\%), and the greatest increase in use occurred among richer respondents where contraceptive prevalence doubled according to the reports of women.

U ptake of hormonal methods

Among current users, $28 \%$ reported adopting a method since acquiring the cassette. Of those already practising family planning about $17 \%$ reported switching methods, the majority to the pill and injectables. Data on changes in method-specific use, from the time of acquiring the cassette to the time of the survey, are presented in Table 7. At the time of acquiring the cassette, condoms were the most popular method. At the time of the survey the pill had become the most popular current method reported by $16 \%$ of women and $12 \%$ of men, while the injectable came second and was used by $9 \%$ of women. 
Couple agreement on current pill use was lower than expected $(\kappa=0.70)$. In fact, in only nineteen couples did both partners report pill use. Among the eleven discordant couples where the woman only reported pill use, six husbands reported no use and five reported another method. Three men claimed pill use while their wife either reported use of injectables or IU D s or no use. Couple agreement on injectable use was higher $(\kappa=0 \cdot 84)$ with five disconcordant couples.

Based on reports of women, half of all current pill users had started using the pill before they obtained the tape (fifteen), eight were not using anything before they got the tape, while seven had switched methods. Nearly $30 \%$ of current injectable users (five out of seventeen) began using the injection prior to obtaining the cassette, three switched from another method, and nine were not using anything at the time they got the tape. Even though prevalence had not increased among the group who received the cassette from friends, four couples did switch to hormonal methods.

Multivariate logistic regression was conducted to measure the net effect of listening to the tape on uptake of hormonal methods. To limit the analysis to motivated couples who had purchased the tape either from a pharmacist or an LHV, couples who got it from friends and other sources were excluded. All data used are those reported by the wife, except for the husband listening to the tape, where his own response is used. The sex of the partner who obtained the cassette was not included in the model since it was highly correlated with source of tape. Since a large proportion of current users were already using pills or injectables at the time they obtained the tape, the impact of the cassette was evaluated among respondents who were non-users (or users of other methods) before they got the cassette. The first model in Table 8 shows that listening to the tape has no significant effect on uptake of hormonal methods (women who listened to the tape were 1.9 times more likely to have adopted a hormonal method than those who did not listen, while the likelihood of adoption reduced by a quarter if the husband had listened to the tape). Since interpersonal contact and advice is important in the adoption of contraception, the source of tape and the attendance of chat groups were included in $\mathrm{M}$ odel 2. A ttending a chat group was a strong and significant predictor of the uptake of a hormonal method (odds ratio $=4.15 ; p=0.018$ ), while the effect of obtaining the tape from an LHV was higher than listening to the tape. (For women an effect is hard to demonstrate, though, since $87 \%$ had listened to the tape.) However, this analysis showed a reassuring lack of negative association between hormonal uptake and husband listening to the tape. None of the sociodemographic variables had a significant independent effect on hormonal uptake after exposure to the tape, but they are included in $\mathrm{M}$ odel 3 to avoid omitted variable bias. Controlling for age of woman, household income and education weakens the effect of listening to the tape and obtaining it from an LHV, while it still increases the net effect of attending a chat group.

\section{D iscussion}

It is too early in the intervention to measure the impact of the cassette on population-based levels of knowledge and use of hormonal methods of contraception. However, important lessons can be learnt from the operations research among 
Table 8. Odds ratios of uptake of hormonal methods by tape determinants

\begin{tabular}{|c|c|c|c|}
\hline & \multicolumn{3}{|c|}{ U ptake of hormonal use $(n=100)$} \\
\hline & Model 1 & Model 2 & Model 3 \\
\hline \multicolumn{4}{|c|}{ Wife listened to tape } \\
\hline Y es & 1.90 & $1 \cdot 81$ & $1 \cdot 56$ \\
\hline No & 1 & 1 & 1 \\
\hline \multicolumn{4}{|c|}{ Husband listened to tape } \\
\hline Y es & 0.74 & 1.01 & 0.99 \\
\hline No & 1 & 1 & 1 \\
\hline \multicolumn{4}{|l|}{ Source of tape } \\
\hline LHV & & $2 \cdot 07$ & $1 \cdot 52$ \\
\hline Chemist store & & 1 & 1 \\
\hline \multicolumn{4}{|c|}{ A ttended chat group } \\
\hline Y es & & $4 \cdot 15^{*}$ & $4 \cdot 51 * *$ \\
\hline No & & 1 & 1 \\
\hline \multicolumn{4}{|l|}{ A ge of wife } \\
\hline$<30$ & & & 1 \\
\hline $30-34$ & & & 0.83 \\
\hline $35+$ & & & 0.30 \\
\hline \multicolumn{4}{|c|}{ Household income (Rs) } \\
\hline$\leq 4000$ & & & 1 \\
\hline$>4000$ & & & $1 \cdot 12$ \\
\hline \multicolumn{4}{|l|}{ Education of wife } \\
\hline None & & & 1 \\
\hline Primary/middle & & & 1.01 \\
\hline Secondary+ & & & 1.28 \\
\hline
\end{tabular}

$* p=0.018 ; * * p=0.016$

couples who had obtained a cassette. Some sampling biases need to be considered in interpreting the results before the prospect of the cassette as a tool for disseminating information and correct knowledge is discussed. Selection bias is suggested as an explanation for the negative attitude among male listeners. A comparison is made of the relative value of distributing the cassette via L H V s versus chemist stores, and the added value of chat groups is highlighted.

\section{Sampling biases}

In this study, contraceptive use increased by nearly a quarter after exposure to the tape, and use of hormonals increased from $12 \%$ to $25 \%$. While this effect is impressive, the impact will be lower in the general population of cassette buyers and listeners for several reasons. Couples who did not give consent for interview are less likely to be users, and respondents who obtained cassettes from LHVs are over-represented. The sampling lists collected from L H V s and chemist stores were not proportional to sales, and more of the addresses collected at chemist stores were 
incomplete or invalid. D istribution figures show that the chemist shops were the main distribution channel in 1997-1998, as they sold 73\% of the cassettes compared with $5 \%$ sold by LHVs; the remainder were given as free packs to doctors and LHVs (L. Palmer, personal communication).

It has recently been suggested that low income acts as a deterrent to use of modern contraception in Pakistan, particularly for those contraceptives provided by the private sector (Agha, 2000). Whereas these data showed a higher increase in overall contraceptive use among the richer couples, socioeconomic background variables were not found to be significant predictors of uptake of hormonal methods in the multivariate analysis. The fact that this study was not done among a random sample of the population, but rather among a self-selected sample of couples (of different socioeconomic strata) who had obtained a tape, may explain the absence of an effect of income.

The cassette as a tool for knowledge dissemination

The cassette is clearly effective in imparting knowledge to those who listen to it. Both women and men correctly recalled information provided on the tape about 4 months after they first obtained the cassette. Face-to-face contact with an LHV or attendance at a chat group had no independent effect on women's knowledge of correct use of hormonals, and the cassette thus seems a promising vehicle to bring accurate information directly to these hard-to-reach women. $\mathrm{H}$ alf of the current pill users had started use before they obtained the tape. For these women, the cassettes may be influential in keeping them satisfied by answering their questions and allaying their fears. The effect of the cassette on discontinuation could not be estimated from these data, but it is an important issue to study in future.

A second objective of distributing the cassettes was to create demand for hormonal contraception, which is important given the government restriction on TV advertising. Indeed, the important benefit of the cassette as a dissemination tool is that it can be shared and discussed with other people. A third of couples had lent out the tape or given it away, but since one tape can be given away more than once, it is difficult to establish from these data how big the multiplication effect might be. A mong couples that were given the tape by friends or neighbours, it was the husband who most frequently received it. Generating discussion about contraception in the community is important in creating demand. A mong respondents who listened, men were more likely than women to discuss the tape with others, though this difference may partly reflect gender differences in admitting discussions about such issues to strangers.

Bringing accurate knowledge to women is essential in promoting hormonal use, but not enough to encourage adoption of these methods. Couple communication about contraception has been shown to be important for the effective uptake of contraception (Barnett, 1998; D rennan, 1998; Podhisita, 1998). Listening to the cassette seems an ideal opportunity for initiating and facilitating discussion about contraception between spouses. However, only a fifth of couples had listened to the tape together, and only 35\% of women reported discussing the content of the tape with her husband. A nother indication of poor communication between spouses is the 
fact that less than two-thirds of husbands whose wives had attended a chat group had knowledge of this fact. The lack of couple agreement on pill use is also striking, with a fifth of husbands of pill users claiming not to practise birth control. This potential secret use by women is higher and contradictory to the common assumption that clandestine users would be more likely to choose injectable use as it is easier to conceal. These relatively poor results on couple communication need to be contrasted with other observations about some women's autonomy in decision-making in this sample. Despite women's limited decision-making powers within households, as has been frequently reported (Hakim \& Salway. 1999; Sathar \& Casterline, 1998), the majority of women in this study (80\%) got the tape without any prior discussion with their spouse. A $45 \%$ increase in contraceptive prevalence for couples with husbands who had not listened to the tape suggests that a lot of men seem to leave the decision to start contraception to their wife.

\section{Are men's negative attitudes attributable to the cassette?}

The more negative attitude expressed by the more involved men, i.e. those who had listened to the tape, is of particular interest. It is important to explore whether it might be attributable to the cassette. Due to the cross-sectional study design, it was impossible to measure attitudes before and after listening to the tape. When inferring change in attitude from the differences between listeners and non-listeners in the 'intention to use hormonals in future', a selection effect must be considered as an alternative explanation. There is evidence to suggest that men's negative attitude pre-dates listening. M ale listeners were less likely to be using contraception at the time they obtained the tape, and nearly half of them had been given the cassette by a friend. They thus constitute a relatively less motivated subgroup of men. In the multivariate analysis, among couples who bought the tape, husbands' listening had no negative effect on uptake of hormonal methods. This supports the argument that these men are not necessarily being adversely influenced against contraception by listening to the tape, but rather that male listeners were a subgroup of more apprehensive men. Other studies have shown that men have not been targeted enough in outreach programmes, and this study strongly supports the call for more consideration of 'men as partners' in reproductive health initiatives in Pakistan (Wegner et al., 1998).

\section{Distribution channel: LHV versus pharmacy}

Face-to-face communication combined with door-to-door community-based provision of family planning services is often seen as the most effective way to increase contraceptive prevalence, especially in a society where female mobility is restricted (K abir \& A mirul Islam, 2000; K han, 1999). While the Pakistani government developed two schemes with community-based female workers in 1992-94 to increase access to family planning, only $16 \%$ of women nationwide reported that they had been visited by a government health worker in the last year (H akim et al., 1998). The private (social marketing) sector has also recognized the importance of interpersonal contact, and uses private LHVs to reach women directly. This study shows that 
contraceptive use and uptake is indeed higher among couples who obtained the cassette from an LHV as compared with the chemist store. Women who benefited from interpersonal contact with an LHV were also more likely to have attended a chat group. However, the higher uptake among these women cannot be attributed to the effect of the LHV or chat group alone, and here too selection effects need to be considered. Couples who obtain the cassette from an LHV are likely to be an inherently different subgroup of the population from those who get the tape in a chemist store. Women who bought the tape from an LHV may also enjoy more autonomy than those whose husband brought the tape home. Through regular interaction with women in her community, the LHV is best placed to target women most interested in family planning, whereas people buying from chemist stores are a more 'self-selected' group. The LHVs clearly did reach a relatively more motivated group, with a higher demand for contraception and a larger proportion of couples already practising birth control. Thus, while the distribution of the cassette through L H V s seems to have a higher impact, the distribution via the chemist store is bound to serve a different subgroup of the population.

\section{A dded value of chat groups}

The chat groups organized by the LHVs seem a promising addition to the standard social marketing activities. The data suggest that LHVs involved satisfied users in these meetings, an idea advocated as effective in outreach activities (Population Council, 1993). A Ithough the discussion groups did not seem to have any net effect on women's knowledge of correct use of hormonals, they seem very effective in giving women the confidence to start using them. Women who had attended a chat group were 4.5 times more likely to have adopted a hormonal method after exposure to the cassette. This finding does not imply that the cassette without the chat group was ineffectual, but reaffirms the undeniable value of interpersonal communication, and of group sessions, with the opportunity to share experiences and fears. However, since all chat group attendees in this study by definition obtained a cassette, they were relatively more motivated than the average woman who attended these meetings.

\section{Conclusions}

The findings show that accurate knowledge can be imparted by the cassette, which is crucial in a setting where widespread erroneous beliefs about health concerns and serious side-effects have affected the uptake of hormonals. The distribution of the cassette has now been extended to the national level. The study gives strong evidence to support the expansion of M ohalla Sangat chat groups since their added value in giving women the confidence to take up contraception is convincing. In further evaluation of this social marketing intervention, this 'added value' will need to be balanced with the added cost of organizing these groups.

$M$ en are clearly a more apprehensive and harder to convince group than women. Those men who are 'most involved' - who obtain the tape themselves and listen to it - are least likely to be current users. Since their negative attitude pre-dates listening to the cassette, this finding calls for more, rather than less, attention to men. 
Equivalent 'male chat groups' are therefore advocated to lessen men's more negative attitudes. It seems clear that men too need interpersonal communication with an opportunity to share doubts and clarify issues in a group mediated by a knowledgeable person.

F or evaluating the impact of the audiocassette in attracting couples to effective use of hormonal methods (both uptake and continuation), a different study design is required. The operations research reported in this paper has served as an important first step in the process of evaluation of this innovative intervention. By providing accurate information to urban couples and by acquiring a knowledgeable critical mass of satisfied users to catalyse change, the cassette may well have a substantial medium- to long-term effect on contraceptive use.

\section{Acknowledgments}

This study was funded by the UK Government's Department for International D evelopment (DFID). The F utures G roup provided the sampling list of people who had bought a KEY cassette. A ftab A ssociates were responsible for data collection, data entry and cleaning. Technical assistance and data analysis were conducted by the London School of $\mathrm{H}$ ygiene and Tropical M edicine. The authors would like to thank the chemist stores and Lady Health Visitors who collected the lists of respondents, and the respondents that gave their time. Thanks go to J ohn Cleland for feedback on an earlier draft of this paper.

\section{R eferences}

A GHA, S. (2000) Is low income a constraint to contraceptive use among the Pakistani poor? J. biosoc. Sci. 32(2), 161-175.

BARNETT, B. (1998) Family planning use often a family decision. Network 18(4), 10-1, 13-4.

DAVIES, J. \& AGHA, S. (1997) 10 years of Contraceptive Social marketing in Pakistan: An A ssessment of Management, Outputs, Effects, Costs and Cost-efficiency 1987-1996. Population Services International, Washington, DC.

D aVIES, J., M ItRa, S. N . \& SChellstede, W. P. (1987) Oral contraception in Bangladesh: social marketing and the importance of husbands. Stud. Fam. Plann. 18(3), 157-168.

D ReNnAN, M . (1998) R eproductive health: new perspectives on men's participation. P opul. Rep. (Series J) 46.

Hakim, A., Cleland, J. \& Bhatti, M. Ul H. (1998) Pakistan Fertility and Family Planning Survey 1996-1997 (PFFPS). Preliminary Report. National Institute of Population Studies \& London School of Hygiene and Tropical M edicine, Islamabad.

H AKIM, A \& S SALWAY, S. (1999) Women's Autonomy and U ptake of Contraception in Pakistan. Conference paper. Dissemination of results of research on reproductive health in Pakistan, Islamabad, A pril.

K ABIR, M . \& I SLAM, M . A. (2000) The impact of mass media family planning programmes on current use of contraception in urban Bangladesh. J. biosoc. Sci. 32(3), 411-419.

K HAN, A. (1999) Mobility of women and access to health and family planning services in Pakistan. Reprod. HIth M atters 7(14), 39-48.

PoDhisita, C. (1998) Gender decision making in family formation and planning: achievement and future direction. J. Popul. soc. Stud. 6(1-2), 1-27. 
Population Council (1993) O perations R esearch Family Planning D atabase Project Summaries. Population Council, N ew Y ork.

Population Council (1997) The Gap between Reproductive Intentions and Behavior: A Study of Punjabi $M$ en and Women. Population Council, I slamabad.

Population Council and M inistry of Population Welfare (1996) Situation Analysis of the V illaged Based Family P lanning W orkers in Pakistan, 1995. Final Report. Population Council, Islamabad.

Sathar, Z. A . \& Casterline, J. B. (1998) The onset of fertility transition in Pakistan. Popul. Dev. Rev. 24(4), 773-796.

Shelton, J. D., Bradshaw, L., Hussein, B., Zubair, Z., D rexler, T. \& M cK enna, M. R. (1999) Putting unmet need to the test: community-based distribution of family planning in Pakistan. Int. Fam. Plann. Perspect. 25(4), 191-195.

W egner, M. N., L ANDry, E., W ILKinson, D. \& Tzanis, J. (1998) M en as partners in reproductive health: from issues to action. Int. Fam. Plann. Perspect. 24(1), 38-42.

Westoff, C. F . \& B AnKole, A. (1995) The potential demographic significance of unmet need. Int. Fam. Plann. Perspect. 22(1), 16-20.

W orld Health Organization (1996) Improving A ccess to Quality Care in Family Planning. M edical Eligibility Criteria for Contraceptive Use. WHO (WHO/FR H/FPP/96.9), Division of F amily and Reproductive Health, Geneva. 